\title{
Remote Scheduling System for Drip Irrigation System Using Geographic Information System
}

\author{
Kadeghe G. Fue, Camilius Sanga \\ Computer Centre, Sokoine University of Agriculture, Morogoro, Tanzania \\ Email: kadefue@suanet.ac.tz, sanga@suanet.ac.tz
}

Received 24 August 2015; accepted 27 October 2015; published 30 October 2015

Copyright (C 2015 by authors and Scientific Research Publishing Inc.

This work is licensed under the Creative Commons Attribution International License (CC BY). http://creativecommons.org/licenses/by/4.0/

\section{(c) (i) Open Access}

\begin{abstract}
The Internet is widely accessible in Tanzania. Most of the technologies used in different organizations have changed to address their functions using web based information systems. In this paper, attempt is made to design software system using geographical information system (GIS) for the spatial and temporal distribution of irrigation supply for large-scale drip irrigation systems in Tanzania. Map based information system has gained popularity after evolution of simple tools to present spatial information using Internet. Due to water scarcity, it is envisioned that by 2050 the world won't have enough water for communities, industries and agriculture. Web based precision irrigation system refers to deployment of remotely precision irrigation services using the application interface that connects to the Internet. Hence, this study presents the GIS in the context of precision farming to achieve precision irrigation strategy with special reference to precision farming of tea in Tanzania. The GIS-based irrigation scheduling system was designed for the scheduling daily drip irrigation water deliveries and regular monitoring of irrigation delivery performance for maximum yield. The "Scheduling" program computes the right amount of irrigation deliveries based on tea water requirements. The "Monitoring" program gives information on the uniformity of water distribution and the shortfall or excess.
\end{abstract}

\section{Keywords}

Precision Farming, Irrigation, Scheduling, GIS, Software, System, Remote Scheduling

\section{Background Information}

Tea yield in Tanzania is primarily limited by insufficient quantity and timing of water and nutrients required for

How to cite this paper: Fue, K.G. and Sanga, C. (2015) Remote Scheduling System for Drip Irrigation System Using Geographic Information System. Journal of Geographic Information System, 7, 551-563. 
optimum growth. In addition, tea quality is significantly affected by traditional and cultural methods used for tea farms in Tanzania [1].

The quality of Tanzanian tea if increased will have a great impact in the world market compared to the current situation [1].

To compare with Florida, drip irrigation has already proved very successful for optimum production of high value horticultural crops such as grapes, citrus and peaches. On the contrary, current methods and instruments of precision agriculture may not be suitable for Tanzania or they may need modification to apply in Africa after extensive research.

[2] states that stakeholders in Tanzania demand for low-cost irrigation systems, reduced electricity bills and pumping costs and also:

- They need for more efficient irrigation systems which demand less water with view to minimizing depletion of water in reservoirs/dams in response to decreasing amounts of rainfall.

- Stakeholders decision (through the Tea Association of Tanzania) embarked on research on crop water management, including drip irrigation and fertigation of tea. This was due to low availability of water due to poor rainfall during 2003/04-2006/07.

- Saving in water for irrigation by up to $50 \%$ is a necessary step for all stakeholders in tea farming.

- Saving in labor for irrigation by $85 \%$ is a necessary measure for all stakeholders in tea farming.

- Producing the highest yield, up to $6070 \mathrm{~kg} / \mathrm{ha}$ is a proposed plan for yield for all stakeholders in tea farming.

Therefore, it's evident that the current decrease in production of tea in Tanzania has been attributed due to unfavorable weather conditions especially poor rainfall in most growing areas. Small-scale farmers of tea need an affordable and effective method to be deployed in their farms at reduced cost or at minimum cost. This can only be attained by a specific irrigation scheduling that is set to optimize the available water resources.

The benefits of having such a system are: reducing monitoring costs, improving the speed of decision making by supporting the decision-makers with real time information, ability to be accessed by everyone and everywhere on the Internet, reducing time and minimizing effort to reach data, high speed, security and capability of having high rate of error handling with new Internet technologies, centralized database that provide a single source of common information for standardization and faster retrieval and selective modification of information [3] [4], and finally the ability to produce reports based on user specified parameters.

\section{Objectives}

In this study, GIS was deployed to improve irrigation strategy with special reference to precision farming of tea in Tanzania. The GIS-based irrigation system algorithm was developed for the scheduling of daily drip irrigation water deliveries and regular monitoring of irrigation delivery performance. The "Scheduling" program was developed to compute the right amount of irrigation deliveries based on crop water requirements. The "Monitoring" program was developed to give information on the uniformity of water distribution and the shortfall or excess [5]. For optimal results, the developed software should be able to be tested and simulated for irrigation scheduling with allowed water stress depending upon farmers selected irrigation requirements, water restrictions and weather conditions. Hence, the following are the specific objectives under this study:

- To create spatial and weather databases for tea farms.

- To design and develop GIS-based software to schedule irrigation.

- To test and simulate the algorithm of irrigation scheduling as per farmers, selected irrigation requirements, water restrictions and weather conditions.

\section{Literature Review}

Precision farming aims to manage production inputs over many small management zones rather than on large zones. It is difficult to manage inputs at extremely fine scales, especially in the case of the tea irrigation system. However, in real sense we expect site-specific irrigation approach to potentially improve the overall water management in comparison to irrigated farms of hundreds of acres. A critical element of the irrigation scheduling and management is the accurate estimation of irrigation supplies and its proper allocation for the irrigation of structures based on the actual planted areas. All irrigation scheduling procedures consist of monitoring indicators that determine the need for irrigation. The final decision depends on the irrigation criterion, strategy and goal. Irrigation scheduling is the decision of when and how much water to apply to a field. 
The amount of water applied is determined by using a criterion to determine irrigation need and a strategy to prescribe how much water to apply in any situation. The right amount of daily irrigation supply and monitoring at the right time within the discrete irrigation unit is essential to improve the irrigation water management of a scheme [5].

Many computerized tools have been used for scheduling irrigation deliveries and improving the irrigation project management. One such tool is a Geographical Information System (GIS). Its use in irrigation management with their large volumes of spatially and temporally distributed data is most beneficial. The GIS capability to integrate spatial data from different sources, with diverse formats, structures, projections or resolution levels, constitute the main characteristics of these systems, thus providing needed aid for those models that incorporate information in which spatial data has a relevant role [5] [6]. This explained about the capability of GIS for decision-making. The possibility of GIS for easily creating and changing scenarios allows the consideration of multiple alternatives of irrigation scheduling, including the adoption of crop specific irrigation management options. Scenarios may include different irrigation scheduling options inside the same project area applied to selected fields, crops, or sub-areas corresponding to irrigation sectors. This allows tailoring irrigation management according to identified specific requirements [7].

The irrigation scheduling alternatives are evaluated from the relative yield loss produced when crop evapotranspiration is below its potential level. Examples of those successful applications are presented by [7] [8] for surface irrigation in the Mediterranean region.

Irrigation scheduling is the farmers decision process relative to "when" to irrigate and "how much" water to apply at each irrigation event. It requires knowledge of crop water requirements and yield responses to water, the constraints specific to the irrigation method and respective on farm delivery systems, the limitations of the water supply system relative to the delivery schedules applied, and the financial and economic implications of the irrigation practice [9]. Irrigation scheduling models are particularly useful to support individual farmers and irrigation advisory services [8].

[8] reported about an irrigation model embedded within the GIS. The data were correlated to digital data sets on soils, agro-climate, land use, and irrigation practice to produce tabular and mapping outputs of irrigation need (depth) and demand (volume) at national, regional, and catchment levels. The GIS approach allows areas of peak demand to be delineated and quantified by sub-basins. The GIS-based modeling approach is also currently being used to administer irrigation needs for irrigated crops [8] [9]. Map and tabular output from the GIS model can provide licensing staff with the information necessary to establish reasonable abstraction amounts to compare against requested volumes on both existing and new license applications for spray irrigation.

The main value of models results from their capabilities to simulate alternative irrigation schedules relative to different levels of allowed crop water stress and to various constraints in water availability [9].

The main limitation of simulation models is that some model computations are performed at the crop field scale for specific soil, crop, and climate conditions, which characterize that crop field and the respective cropping and irrigation practices. When the computation procedure is applied at the region scale it becomes heavy and slows due to the need to consider a large number of combinations of field and crop characteristics to be aggregated at sector or project scales [7].

Proper irrigation scheduling can reduce irrigation demand and increase productivity. A large number of tools are available to support field irrigation scheduling, from in-field and remote sensors to simulation models. Irrigation scheduling models are particularly useful to support individual farmers and irrigation advisory services [10].

[11] outlined applications of GIS-based modeling. For financial analyses, GIS is used to quantify and map the total financial benefits of irrigation (\$/ha) and the financial impacts of partial or total bans on abstraction for irrigation. Irrigation water requirements are determined by mapping the spatial distribution of water requirements based on soil and crop distributions. GIS-based modeling approaches are used to establish irrigation scheduling based on water-balance modeling.

GIS databases for irrigation include coverage for crops, irrigation methods, and soils. These data are coupled with agro-climatic data to provide information on growing-season and water-use requirements.

As previously stated that the economic benefits of having such a system are: reducing monitoring costs, improving the speed of decision making by supporting the decision-makers with real time information, ability to access by everyone and everywhere over the Internet, reducing time and minimizing effort to reach data, high speed, security and high rate of error handling with new Internet technologies, having centralized database that 
provides a single source of common information which provide standardization and faster retrieval and selective modification of information, and finally, the ability to produce reports based on user specified parameters [3].

\section{Materials and Methods}

\subsection{GIS-Based Irrigation System Scheduling Model}

GIS tools and integrated models find extensive application for scheduling of water applications for an irrigation system. The GISAREG model is representative of a GIS-based modeling package directed to improving irrigation scheduling. The model uses the ArcView software and Avenue scripting language to integrate the spatial and attribute databases with legacy irrigation-scheduling models. The model can be applied for different water-management scenarios and produces crop irrigation maps and time-dependent irrigation depths at selected aggregation levels, including the farm scale. GISAREG simulates alternative irrigation schedules relative to different levels of allowed crop water stress as well as various constraints in water availability. The irrigation scheduling alternatives are evaluated from the relative yield loss produced when crop evapotranspiration is below its potential level [7].

GISAREG inputs are precipitation, reference evapotranspiration, total and readily available soil water; soil water content at planting; and crop factors relative to crop growth stages, crop coefficients, root depths, and water-yield response factors. Various time-step computations are possible, from daily up to monthly, depending on weather data availability. GISAREG model results include annual crop irrigation requirements $(\mathrm{mm})$, readily available water at the beginning and end of the irrigation period $(\mathrm{mm})$, total available water in deep soil layers at the beginning of the irrigation $(\mathrm{mm})$, percolation due to excess of irrigation $(\mathrm{mm})$, precipitation during the irrigation period $(\mathrm{mm})$, non-used precipitation $(\mathrm{mm})$, cumulated actual and maximum evapotranspiration $(\mathrm{mm})$, and monthly irrigation requirements (mm). Results are displayed on map and tabular formats.

The proposed system in this study used GISAREG model with some moderation in order to achieve the model that is intended for tea farms. This approach was taken since GISAREG can accommodate more crops but the goal was to develop crop specific scheduling system.

\subsection{Soil-Water Content Balance Computations for Tea Farm}

The standard method adopted for the calculation of crop water requirements is based on the evaporative demand of the crops for the prevailing stage of growth. There is potential for structuring information to improve the irrigation deliveries, and to develop an information system to improve decision-making in the operation and management of the scheme.

Hydrologic models are valuable tools for water resources management. For irrigation scheduling and cropwater requirement estimation, hydrologic simulation models commonly used the water balance approach [12].

On the other hand, using the soil moisture neutron probe (SMNP) to measure soil water content and determine the optimal irrigation rates and schedules is required to ensure a high yield.

Theoretically, a quantitative estimation of major components of field water balance (Figure 1) is important for improving water delivery performance. The main components are humidity, rainfall, temperature, sunshine hours, wind speed, transpiration and evaporation. Analysis of water balance can give management decisions on how the scheme ought to be operated to ensure better distribution of irrigation water to the service areas. The components of the water balance model for a tea field for a given period are as follows:

- MDx is moisture content depth in the field on the xth day, cm;

- $\mathrm{MD}(\mathrm{x}-1)$ is moisture content depth in the field on the $(\mathrm{x}-1)$ th day, $\mathrm{cm}$;

- IRx is amount of irrigation water supplied on the xth day, cm;

- ERx is rainfall received on the xth day, $\mathrm{cm}$;

- ETx is crop evapotranspiration on xth day, $\mathrm{cm}$;

- DRx is drainage requirement on the xth day, cm;

- $\mathrm{x}$ is irrigation period, day.

Hence, the generalized water balance equation for tea field can be expressed as follows:

$$
\mathrm{MDx}=\mathrm{MD}(\mathrm{x}-1)+\mathrm{IRx}+\mathrm{ERx}-\mathrm{ET} \mathrm{x}-\mathrm{DRx}
$$

ETx is the rate of evapotranspiration measured from a large area, covered by green grass, 7 to $16 \mathrm{~cm}$ tall, 


\section{Hydrological Cycle}

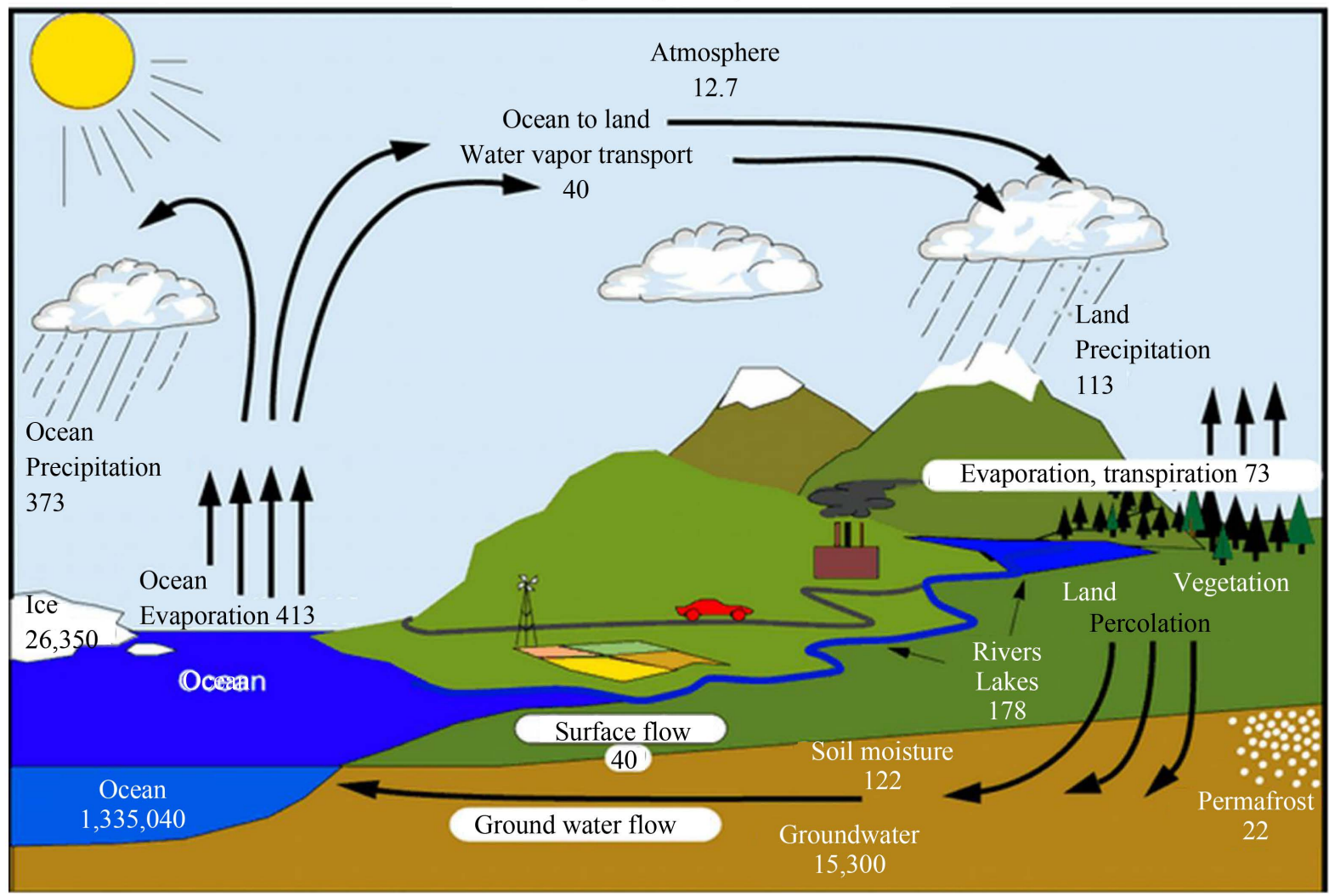

Units: Thousand cubic $\mathrm{km}$ for storage, and thousand cubic $\mathrm{km} / \mathrm{yr}$ for exchanges

Figure 1. Hydrological cycle (https://waterdropblog.files.wordpress.com/2008/06/01_hydrologicalcycle.gif).

which grows actively, completely shades the ground and which is not short of water. The ETx is usually expressed in millimetres per unit of time, e.g. $\mathrm{mm} /$ day, $\mathrm{mm} / \mathrm{month}$, or $\mathrm{mm} / \mathrm{season}$. It can be determined experimentally using an evaporation pan, or theoretically, using measured climatic data, e.g. the Blaney-Criddle method. Since this study is not about finding ETx, we shall assume a table of the ETx as below for our scheduling computations. ETx is calculated for each field so as to have accurate information. Table 1 shows the average Daily ETr estimated for each site so as to model the soil water requirement algorithm.

\subsection{Scheduling Irrigations}

The equation used [13] to estimate the irrigation requirement (IR) per plant is:

$$
\mathrm{GIR}=[(\mathrm{CA} \times \text { Plant Factor } \times \mathrm{ETx})-\mathrm{ER}] \div \mathrm{IE}
$$

where

GIR = the gross irrigation requirement in $\mathrm{mm} / \mathrm{d}$;

$\mathrm{CA}=$ plant canopy area in square $\mathrm{mm}$;

Plant Factor $=0.95$ for tea (approximated and it may need to be researched);

$\mathrm{ETx}=$ reference ET;

$\mathrm{ER}=$ expected rainfall $\mathrm{mm} / \mathrm{d}$;

IE = irrigation efficiency (assume $90 \%$ or 0.90 for low-tech drip system). These are the ones used in Tanzania for irrigation of tea farms.

If the overall water requirement is met by utilization of rainfall during crop growing period, then the net irrigation requirement on a particular day shall be determined by using the following formula:

$$
\operatorname{IRx}=\mathrm{MDx}-\mathrm{MD}(\mathrm{x}-1)-\mathrm{ERx}+\mathrm{ETx} \quad \text { (refer above equations) }
$$


Table 1. Average daily ETr (inch/day) estimates for different sites.

\begin{tabular}{ccccccc}
\hline & \multicolumn{3}{c}{ Month } & & \\
Sites & April & June & July & Aug & Sept & October \\
\hline Field 1 & 0.45 & 0.42 & 0.39 & 0.38 & 0.35 & 0.32 \\
Field 2 & 0.41 & 0.45 & 0.42 & 0.39 & 0.30 & 0.28 \\
Field 3 & 0.43 & 0.42 & 0.40 & 0.39 & 0.38 & 0.35 \\
\hline
\end{tabular}

\subsection{Database Analysis and Design}

[10] have highlighted the building up of databases within a GIS for efficient water management. A coordinated approach at different levels of the irrigation system is required for improving irrigation management. The estimation of irrigation delivery, its schedule and duration is a key element in any irrigation system. This decision-making process is referred to as irrigation scheduling, the use of water management strategies to prevent over-application of water while minimizing yield loss due to water shortage or drought stress.

The GIS database is constituted by point, line and polygon themes data. Weather data refers to one or more years. Weather information is quite necessary for decision making. Accumulation of the weather data series are used, multiple simulations are performed to determine the frequency of crop water and irrigation requirements, or to perform an irrigation planning analysis relative to selected years such as dry, average and wet seasons.

The data should be stored in ASCII files format according to database requirements:

1) The moisture estimation table, including: MDx is moisture content depth in the field on the xth day, cm; IRx is amount of irrigation water supplied on the xth day, $\mathrm{cm}$; ERx is rainfall received on the xth day, $\mathrm{cm}$; $\mathrm{x}$ is irrigation period, day. This data is stored according to specific-areas(polygon coverage) of the farm

2) The farm fields (sensorLoc) table, containing the spatial and non-spatial information of the field that includes sensor ID and coordinates.

3) The evapotranspiration table, containing the sensor ID, evapotranspiration month and value ET.

4) The scheduling table, including the GIR = the gross irrigation requirement in $\mathrm{mm} / \mathrm{d}, \mathrm{CA}=$ plant canopy area in square $\mathrm{mm}, \mathrm{ER}=$ expected rainfall $\mathrm{mm} / \mathrm{d}$ and date calculated

\subsection{General Architecture of the System}

[6] suggested that in 3-tier architecture of GIS-based systems, the functional part of architecture includes a mapping service which produces and displays maps to the users. The mapping service interacts with the database service in order to retrieve data from the database, as required. File and communications services are only required in particular scenarios. The file service writes data into XML files, while the communications service interacts with other remote applications (like sensors) in order to receive live feeds of data, as required. In this research, user interface was used to interact with the mapping tool and application tool that collects data from the field and all data stored into the database. The mapping tool query the information from the database and present it into a user interface (web based mapping tool). Figure 2 shows the relationships between different units of the system. User interface (front end tier) provides interactive tool that a user can communicate or request or query information from the system. There are middle tier applications that collect information from the farm or interact with Application Programming Interface (API) to get instant information of the farm. It is integrated with the application that can interpret geo-referenced data received from the farm. This application communicates with Google maps to provide state of art interface that can be interpreted by a farmer. For storing data, the system uses mySQL database to store all the collected field information.

\subsection{Development of the Irrigation Scheduling Software}

[5] stated that a program using GIS was developed for the spatial and temporal distribution of irrigation supply for a large-scale rice irrigation project in Malaysia. Their study focused on determining water deliveries on a periodic basis during the main (wet) and off (dry) seasons based on spatial and temporal demand. A water balance equation was used to determine the release for each constant head orifice (CHO) within the blocks and compartments. 


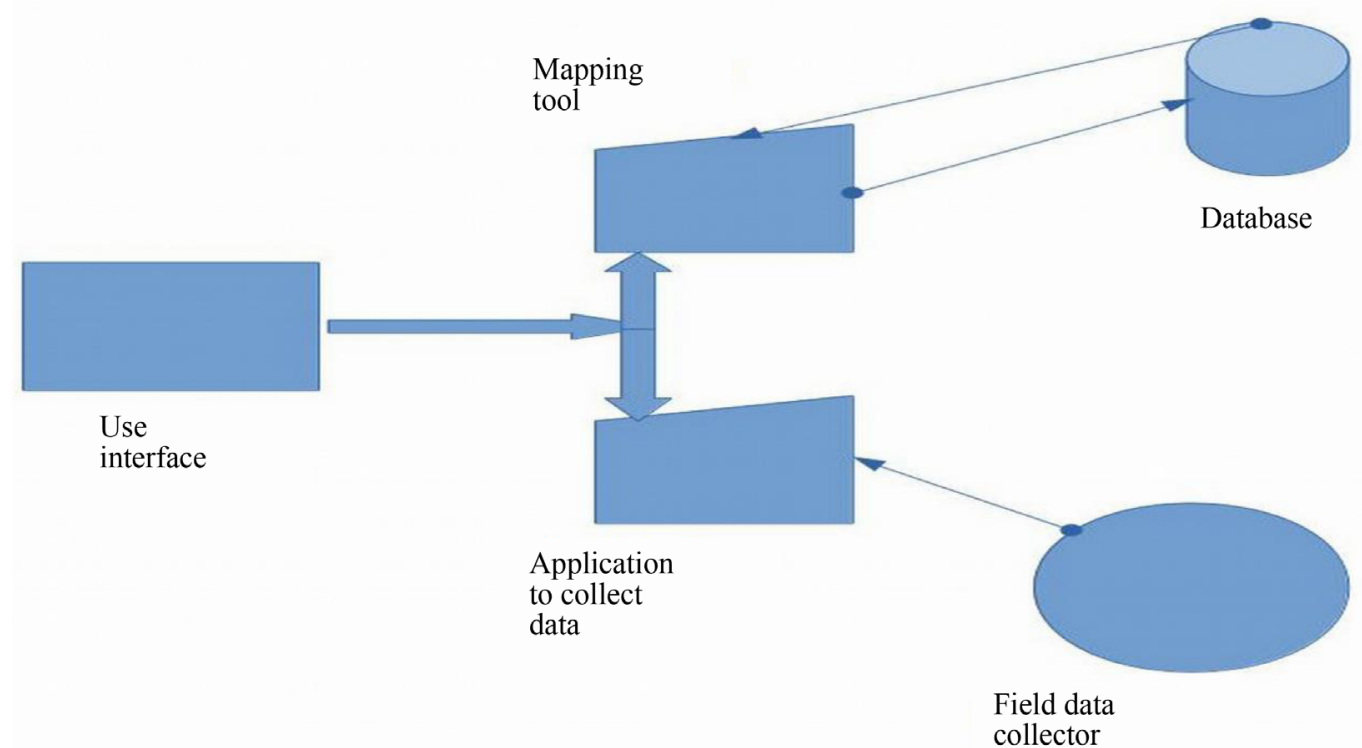

Figure 2. Three-tier web-based GIS applications architecture.

A user interface allows for the selection of a specific area and input of relevant information. The recommended discharges are displayed allowing the manager to view maps, tables and graphs. These provided a basis for decision making as the season progresses.

[6] states that the Google Maps API for Flash and the Flex API for ArcGIS Server allow users to use flex to embed the functionality of Google Maps or ArcGIS maps into web applications. Both APIs manage complex connectivity using the GIS package. They provided an easy to use interface for developers in order that Flash can be used to develop more interactive and rich Internet applications by users who do not need to understand Flash Action Scripts. This opens up a new way of developing GIS applications whereby the GIS server produces the map and then, Flash is used to add some more information to it. This information might entail adding a point, line or polygon, or equally might entail adding some more complex graphics to the map, e.g. custom navigation Flash controls.

In this study, decision support software system was designed and developed using Visual Basic (VB.NET) environment as a user interface platform and Google maps APIs as a GIS component. For creating treatment maps, then a popular open source class gmap.NET is used. Gmap.NET was great and powerful, free, cross platform, open source. NET control enable use routing, geocoding, directions and maps from Google, Yahoo!, Bing, Open Street Map, Arc GIS, Pergo, Sig Pac, Yandex, Mapy.cz, Maps.lt, iKarte.lv, Near Map, Ovi Map, Cloud Made, Wiki Mapia, MapQuest in Windows Forms and Presentation. It supports caching and runs on windows mobile. Hence, we developed functions that are useful for irrigation practices such as view maps, tables and graphs, updates, visualization, reports and irrigation schedule.

(http://greatmaps.codeplex.com/).

\subsection{Google Online Maps}

The software needs online maps from Google maps APIs. The system guided the users in seeing the farm and its' field sensors location online. The system can be integrated with switches to allow control of irrigation distantly. The maps display the fields and sensors allocation that is important to the farm manager. Many decisions in farm depend on spatial information from the day of planting to the day of harvest. Analysis like Yield maps can be produced by such maps. Figure 3 depicts the software showing how sensors are allocated at the farms. The system has been customized to view the Ngwazi Estates in Tanzania. Figure 3 shows the location of Ngwazi estate in Tanzania.

The system directly views the estate using Google maps using geo-reference information of the Ngwazi Tea estates. The center of the Ngwazi estate is estimated at the coordinate $(-8.526253,35.175208)$. Figure 3 shows 


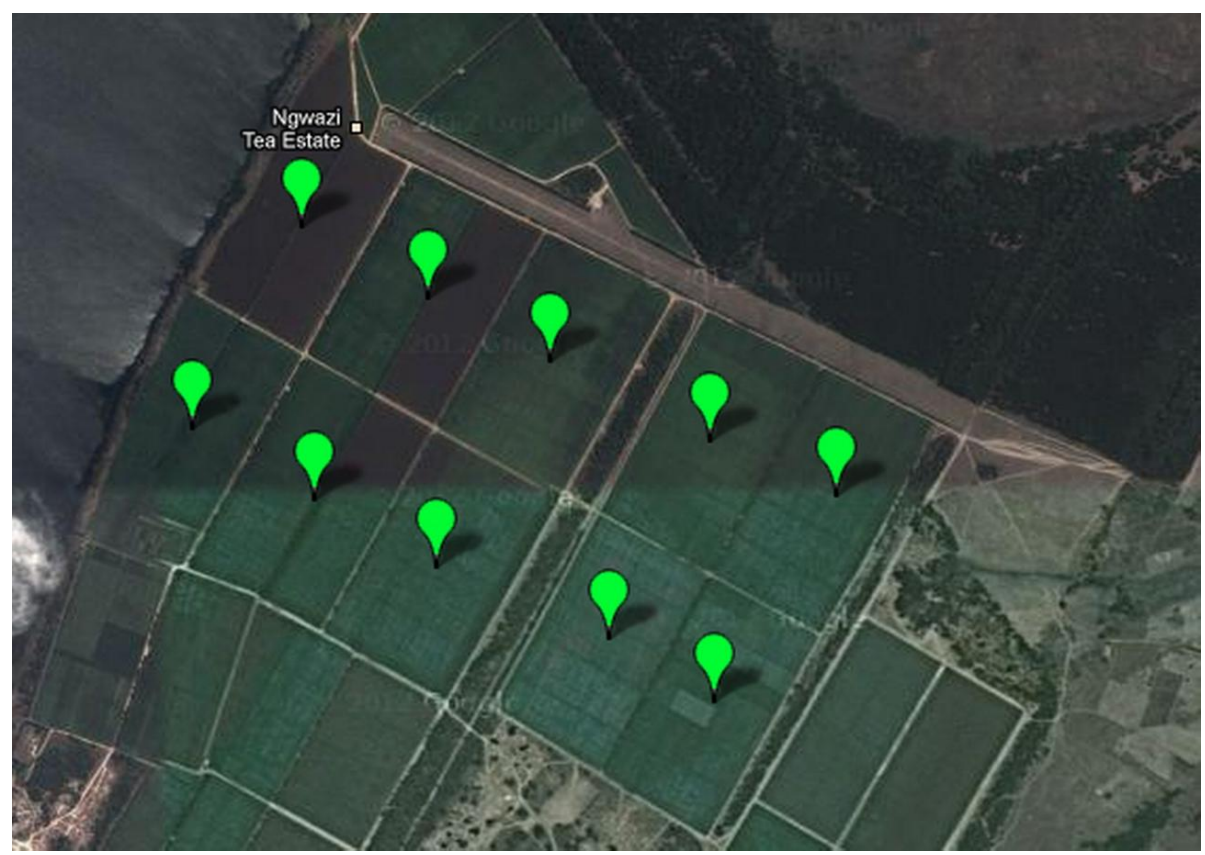

Figure 3. Ngwazi tea estate (portion of the farm).

the map based information from the system. Figure 3 shows points on the middle of each plot/field. There are 10 mid-points of the field. Each field is approximately 1 acre of the farm. Sensor location is shown by the pointers.

\subsection{Moisture Estimation}

The system developed provides a dialog box for water estimation. Information gathered from the sensors (rainfall, irrigation and moisture content) is crucial for estimation of the water that is lost due to several conditions like evapo-transpiration, run off etc.

In this system (Figure 4), the information is entered manually, but the effective way of entering data should be automatically or using a text file created by the sensor microcontroller or using API to query data from external data suppliers like satellite stations. Using the window below then we can enter the information obtained from the sensors. The user can click moisture Est button, the window (Figure 5) pops to receive moisture information of the specific sensor. For example, the sensor ID presents field sensor number. Each field has soil moisture sensor and the information can entered using the window manually.

After that, the user can be able to view the information using the system Geo-referencing window. By hovering the mouse then the information will be displayed instantly. The picture below shows the information from the sensor number at the center of the field number 8 (Figure 4). Also, using the export data button (Figure 4) then we can export the information easily.

\section{Results and Discussions}

\subsection{Scheduling System and Formulas Used}

The algorithm that has been used in the developed system is simple hence, more tests are needed to prove that it is efficient to use in intended fields. Nevertheless, the formulas have proven superiority in estimation of the Irrigation water. In scheduling, there is a button to click and choose and fill the appropriate fields and execute schedule. Go and see the results that have been created by the system. This spatial information will guide the farm manager to know exactly the need of the farm for the next day. Actually, knowing water required for irrigation is so crucial for farms that are in Tanzania due to drought conditions. Despite of Lake Ngwazi being near the farms sometimes water becomes the problem due to drought. The window below allows the prediction of the next day. The estimation needs the expected rainfall in hand, as the system cannot schedule without forecast 

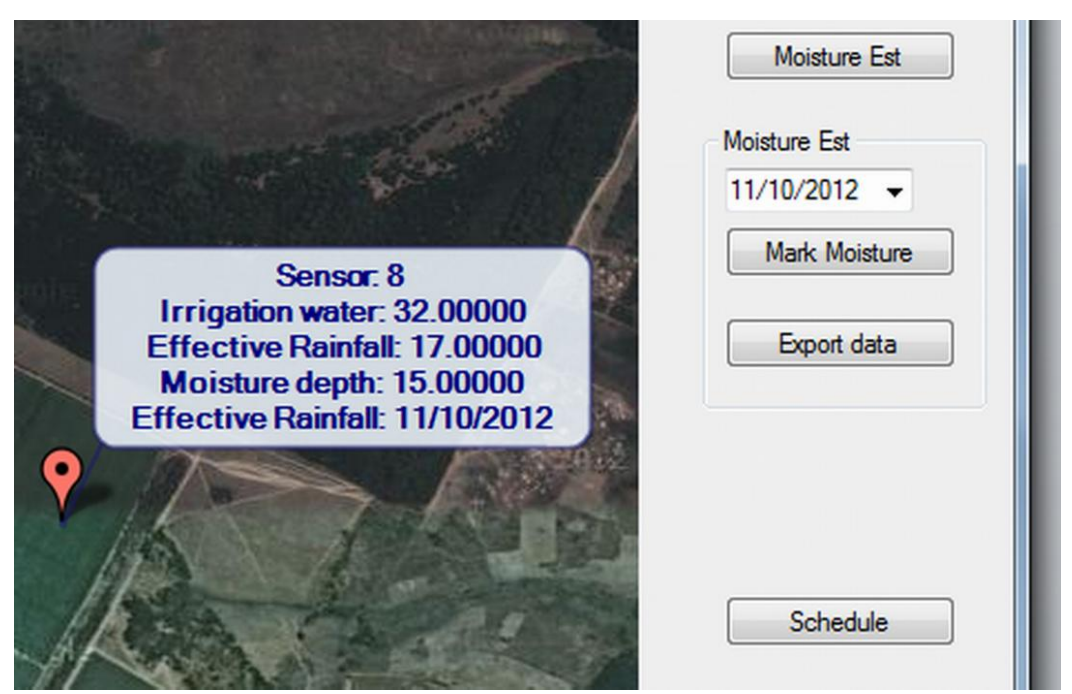

Figure 4. Georeferenced irrigation information.

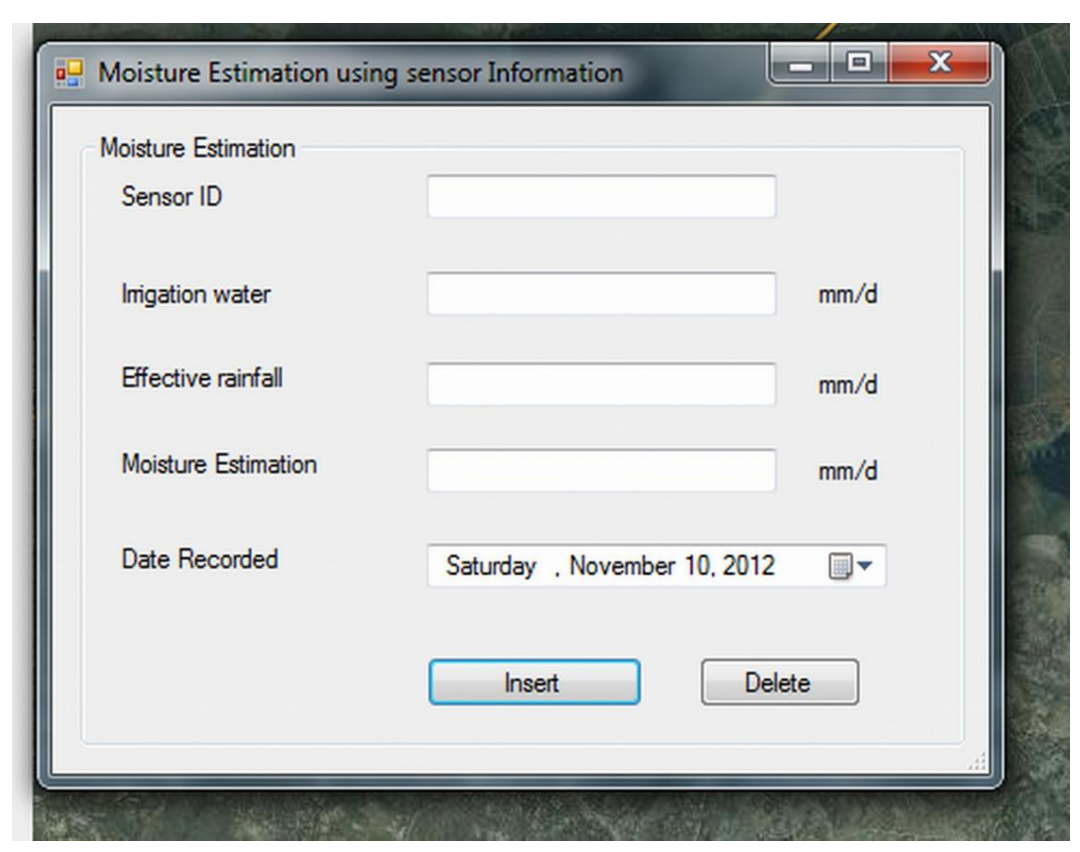

Figure 5. Moisture estimation window.

information of the rainfall. By clicking Schedule button as shown in Figure 4 then scheduling window (Figure 6) pops to provide the information and schedule irrigation for tomorrow.

The scheduling window schedules the data for the next day. In fact, we expect this process to be automated if it is using microcontroller controlled system. When a user chooses Schedule for tomorrow then the system computes Gross irrigation requirement in $\mathrm{mm} / \mathrm{d}$ and then checks if it's positive or negative. Negative will mean that the rainfall is very high for tomorrow hence there is no need to schedule for Irrigation.

\subsection{Post-Processing of the Exported Information from the System}

The system is able to export information (Figure 7) from the database hence extra processing with the exported data is possible. The system can export moisture information using the export data button.

Then, the user presses export data to excel button. This allows the user to have an exported Excel file that can be manipulated using ARCGIS. 


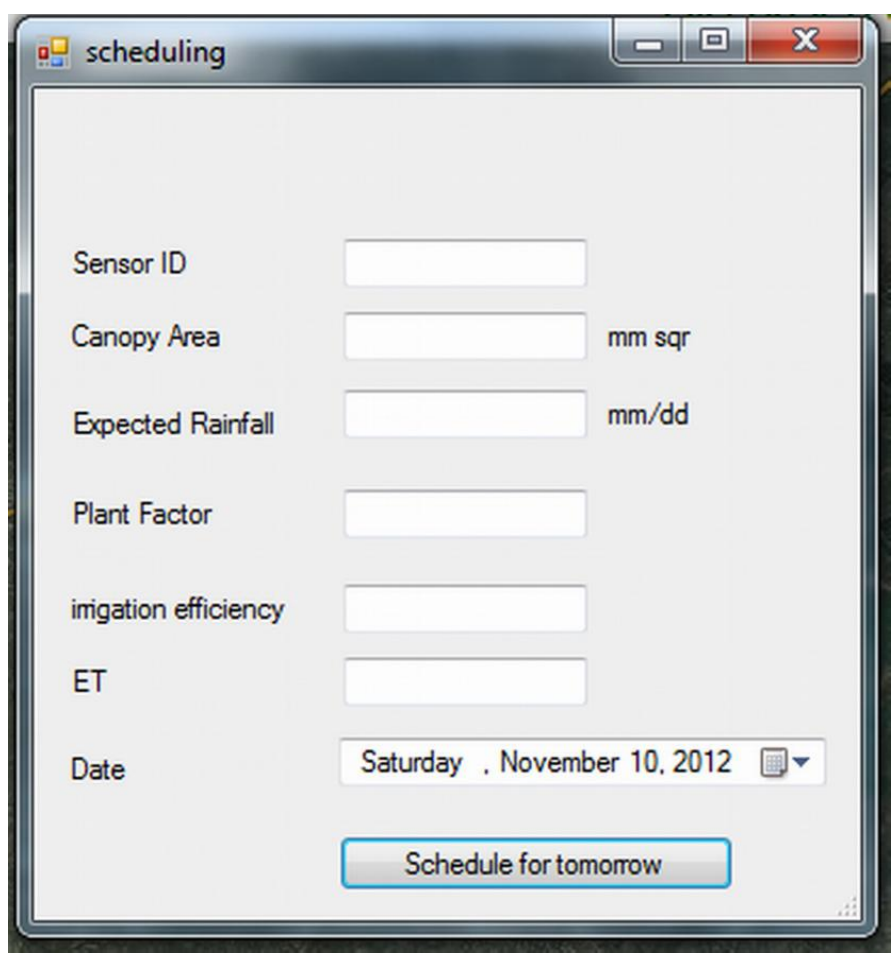

Figure 6. Scheduling window.

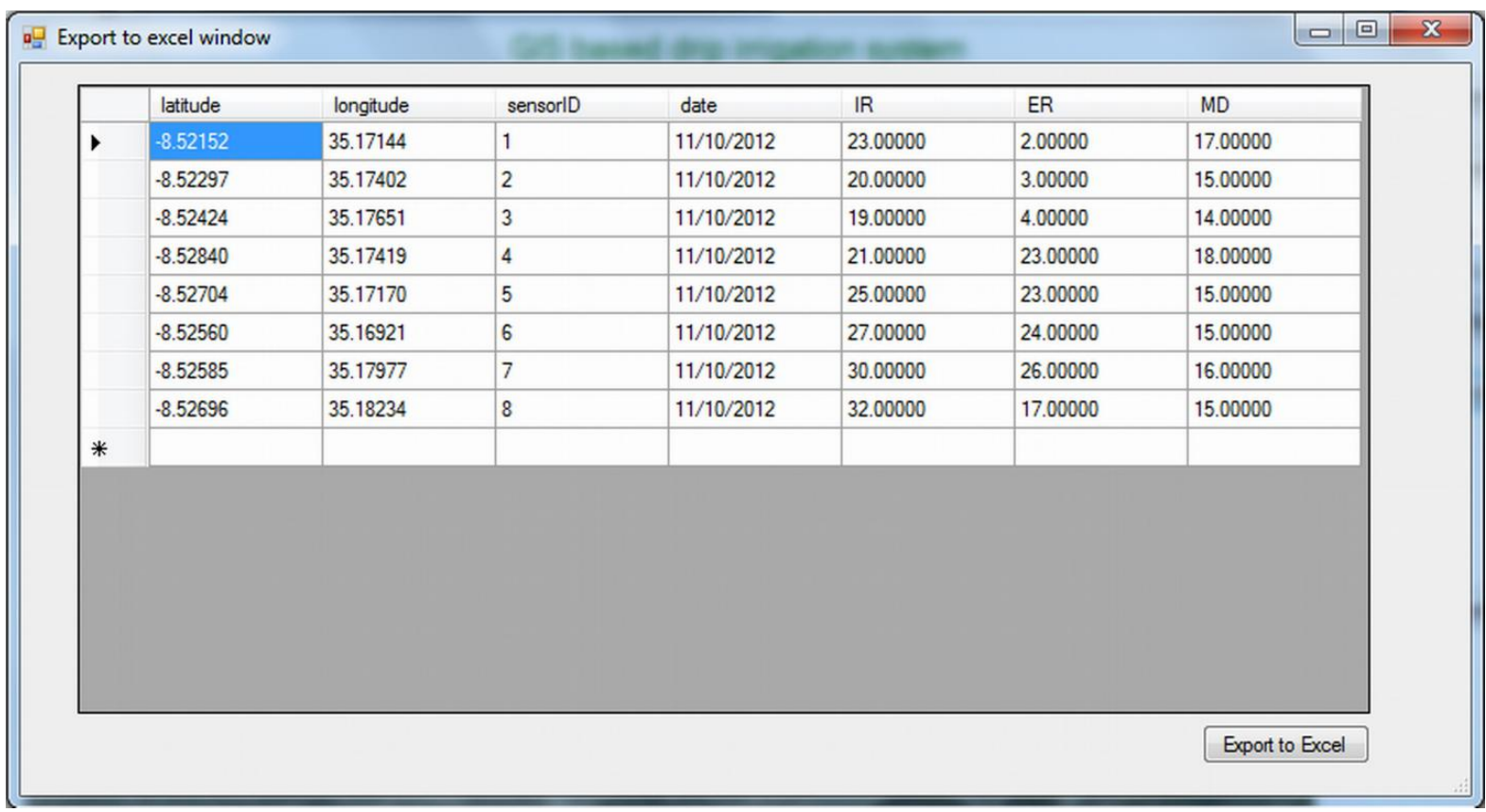

Figure 7. Export data window.

\subsection{Analysis with ARCGIS}

The exported data can be interpolated and analysed to see the distribution of the irrigation water and rainfall. In general, the expectation is a place with the lowest rainfall have an excess irrigation water while vice versa is also true. Therefore, this information related with Moisture depth of the soil so that other soil factors that influence Plant growth can be predicted. Consider the layout view of the irrigation water and rainfall below respectively. 
Looking at both maps (Figure 8 and Figure 9), we can realize that contradiction occurs at south east of the map were more irrigation more rainfall. This area indicates special site-specific characteristics. The soil of this

Irrigation Water distribution in Ngwazi tea estates

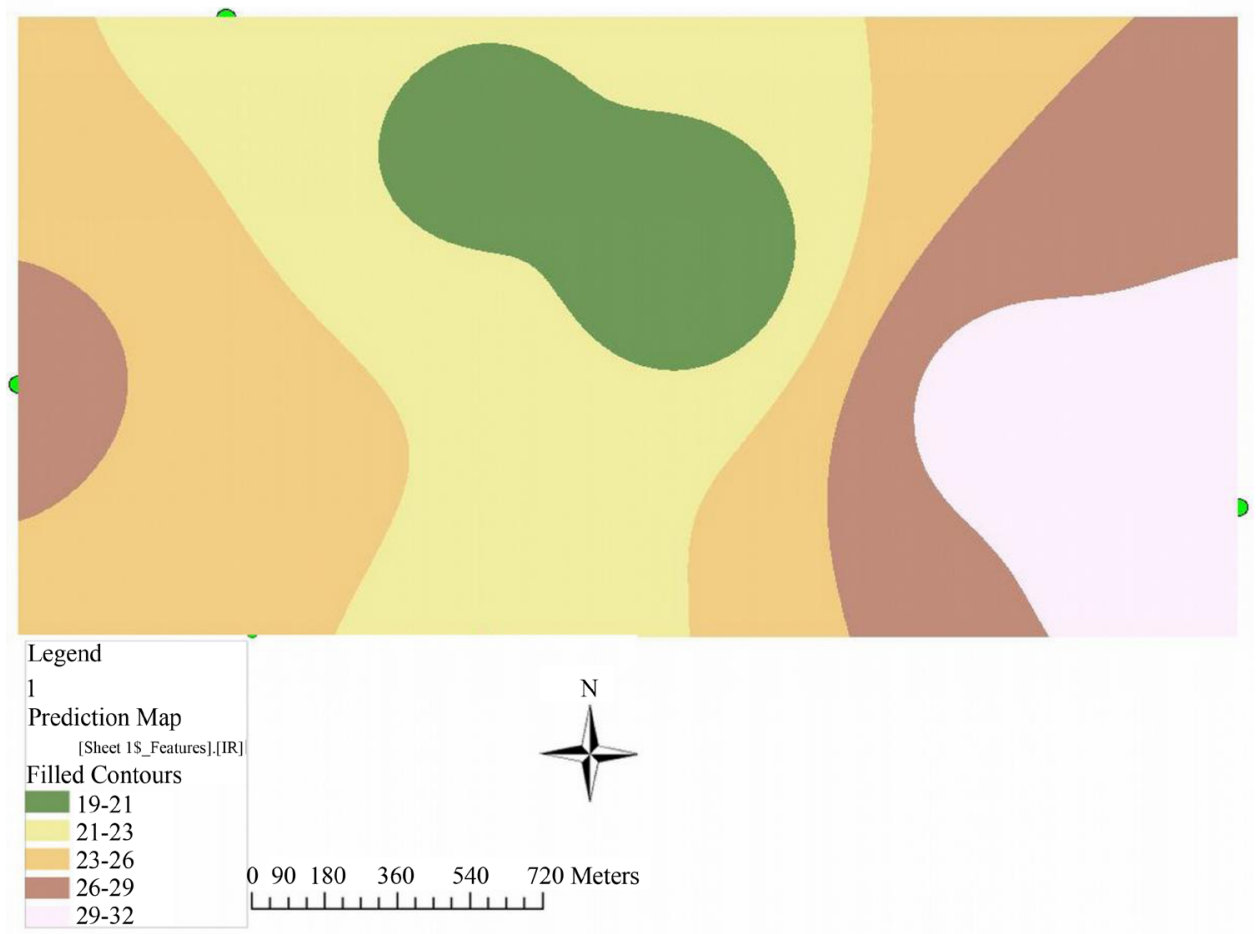

Figure 8. Irrigation water distribution.

Rainfall distribution in Ngwazi Teai Estates

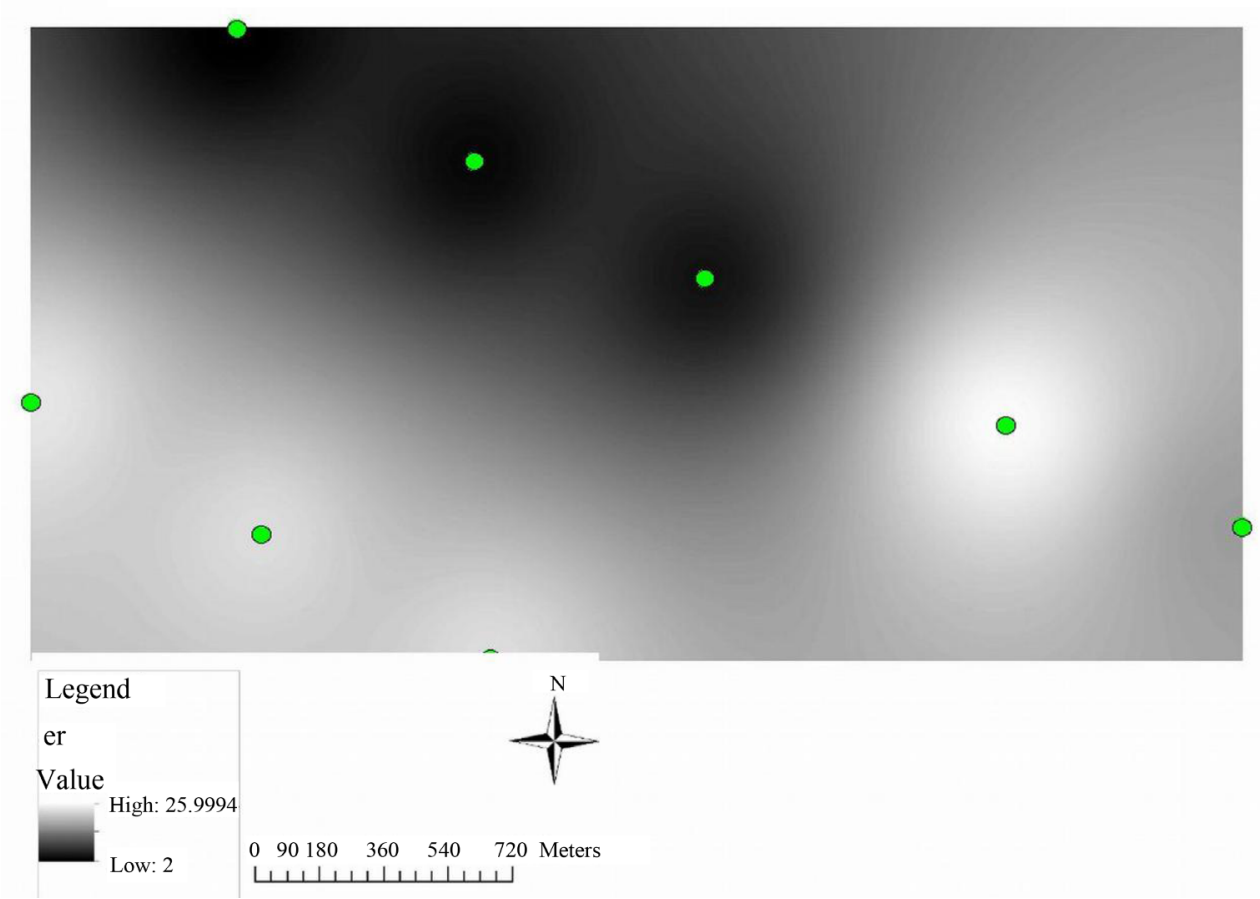

Figure 9. Rainfall distribution in Ngwazi tea estates. 
place cannot hold water hence it needs more irrigation in high rainfall conditions. That means, it will consume more irrigation water. This place will need more sensors to measure moisture in small areas. This indicates the water table might be far away deep. In this sense, water in these areas will often be monitored so that the soil stays wet for acceptable crop production.

Further at the centre (Figure 9), while heading north, the site has low rainfall and low irrigation too. In fact this indicates that the place is so wet all season due to high water holding capacity of its soil. Such soil can retain water for further period hence its scheduling and monitoring might be loose as no any significant effect to low irrigation.

\section{Conclusions}

It's true that the necessity of achieving sustainable management of available water resources for irrigation supplies will determine the development of up-to-date and competitive agriculture. The information from developed system in this study is essential to assess crop water status and to efficiently irrigate tea crop as well as for improving water management. GIS with map-based user-interface technique linked with water management model can greatly assist to improve water management based on feedback from field information. This study presents comprehensible results along with new data sets and can assist irrigation managers to improve the decision-making process in the operation and management of the irrigation system. The system can improve the management of water allocation systems and scheduling water distribution system in existing schemes. This study has indicated that improvements in irrigation system management based on feedback of field information can satisfy the role of the precision agriculture. The system developed from this research actually provides an alternative approach to desktop way of evaluating data. Remote scheduling provides distant control over the conventional method where in field presence is required for monitoring of the crop. This gives managers an opportunity to get crop water conditions of the field while distantly located compared to the existing desktop monitoring where data need to be sent through email or whatever inconvenient existing methods. Interactive graphs provide great opportunity to monitor water.

In order to reduce costs, software developed from this study is necessary such that precision farming can be practiced to reduce wastes, minimize costs and improve crop yield and hence, increase profit in the same farm.

\section{References}

[1] Official Online Gateway of the United Republic of Tanzania. http://www.tanzania.go.tz/agriculture.html

[2] Kingalu, J. (2008) Drip Irrigation and Fertigation of Tea. Developing Agricultural and Agri-Business Innovation in Africa. http://info.worldbank.org/etools/docs/library/243684/session2aTzCaseStudiesTeaIrrigationMFPs.pdf)

[3] Montgomery, G.E. and Schuch, H.C. (1993) GIS Data Conversion. GIS Data Conversion Handbook, 27-45. http://dx.doi.org/10.1002/9780470173244.ch2

[4] Ozdilek, O. and Seker, D.Z. (2004) A Web-Based Application for Real-Time GIS. http://www.isprs.org/proceedings/XXXV/congress/yf/papers/934.pdf

[5] Rowshon, M.K. and Amin, M.S.M. (2010) GIS-Based Irrigation Water Management for Precision Farming of Rice. International Journal of Agriculture and Biological Engineering, 3, 27.

[6] Adnan, M., Singleton, A.D. and Longley, P.A. (2010) Developing Efficient Web-Based GIS Applications. CASA Working Papers Series, Paper 153.

[7] Fortes, P.S., Platonov, A.E. and Pereira, L.S. (2005) GISAREG: A GIS-Based Irrigation Scheduling Simulation Model to Support Improved Water Use. Agricultural Water Management, 77, 159-179. http://dx.doi.org/10.1016/j.agwat.2004.09.042

[8] Zairi, A., El Amami, H., Slatni, A., Pereira, L.S., Rodrigues, P.N. and Machado, T. (2003) Coping with Drought: Deficit Irrigation Strategies for Cereals and Field Horticultural Crops in Central Tunisia. In: Tools for Drought Mitigation in Mediterranean Regions, Springer, Netherlands, 181-201. http://dx.doi.org/10.1007/978-94-010-0129-8 11

[9] Pereira, L.S., Teodoro, P.R., Rodrigues, P.N. and Teixeira, J.L. (2003) Irrigation Scheduling Simulation: The Model ISAREG. In: Rossi, G., Cancelliere, A., Pereira, L.S., Oweis, T., Shatanawi, M. and Zairi, A., Eds., Tools for Drought Mitigation in Mediterranean Regions, Kluwer, Dordrecht, 161-180. http://dx.doi.org/10.1007/978-94-010-0129-8_10

[10] Rowshon, M.K., Kwok, C.Y. and Lee, T.S. (2003) GIS-Based Scheduling and Monitoring of Irrigation Delivery for Rice Irrigation System: Part I. Scheduling. Agricultural Water Management, 62, 105-116. 
http://dx.doi.org/10.1016/S0378-3774(03)00092-1

[11] Ortega, J.F., De Juan, J.A. and Tarjuelo, J.M. (2005) Improving Water Management: The Irrigation Advisory Service of Castilla-La Mancha (Spain).Agricultural Water Management, 77, 37-58. http://dx.doi.org/10.1016/j.agwat.2004.09.028

[12] Teixeira, J.L. and Pereira, L.S. (1992) ISAREG, An Irrigation Scheduling Model. ICID Bulletin, 41, 29-48.

[13] Allen, R.G., Pereira, L.S., Dirk, R. and Martin, S. (1998) Crop Evapotranspiration: Guidelines for Computing Crop Water Requirements. FAO Irrigation and Drainage, Rome, Paper-No 56. 